\title{
Análise produtiva e econômica do pimentão-vermelho irrigado com diferentes lâminas, cultivado em ambiente protegido ${ }^{1}$
}

\author{
Jacinto de A. Carvalho ${ }^{1}$, Fátima C. Rezende ${ }^{2}$, Reinaldo F. Aquino ${ }^{2}$, \\ W ellington A. de Freitas ${ }^{2} \&$ Eduardo C. O liveira ${ }^{2}$
}

\begin{abstract}
RESU MO
0 manejo da irrigação é importante não apenas por suprir as necessidades hídricas das culturas mas, também, por minimizar os problemas de doenças, lixiviação de nutrientes e gastos com consumo de água e energia. O bjetivou-se, com o presente trabalho, uma avaliação técnica e econômica da produção do pimentão-vermelho em função de lâminas de irrigação. 0 experimento foi instalado em ambiente protegido, com delineamento inteiramente casualizado (DIC), com cinco tratamentos de reposição de água no solo $(50,75,100,125$ e $150 \%)$ e quatro repetições. Os resultados permitiram concluir que 0 número de frutos por planta, o peso médio dos frutos e, consequentemente, a produção por planta, foram afetados pelos níveis de reposição de água no solo. A máxima produtividade foi de $35.300 \mathrm{~kg} \mathrm{ha}$ ${ }^{1}$ com a aplicação de $443,9 \mathrm{~mm}$ e a lâmina ótima econômica foi estimada em 443,5 mm. O s maiores retornos econômicos são obtidos mantendo a cultura com umidade próxima da capacidade de campo, repondo integralmente a quantidade de água consumida. A maior eficiência no uso da água foi estimada em 74,76 kg ha-1 $\mathrm{mm}^{-1}$, com a aplicação de $334,1 \mathrm{~mm}$.
\end{abstract}

Palavras-chave: Capsicum annuum L., função de produção, lâmina ótima econômica

\section{Productive and economic analysis of red-pepper under different irrigation depths cultivated in greenhouse}

\begin{abstract}
The irrigation management is not only an important factor to supply plant's water needs, but also to minimize problems with diseases, nutrient leaching as well as unnecessary expenses with water and energy. This study had the aim to verify the economic feasibility of red bell pepper (Capsicum annuum, L.) yield under different irrigation depths, cultivated in greenhouse. A completely randomized design (CRD) was used, with five levels of replacement of irrigation water $(50,75,100,125$ and 150\%) with four replications. Significant differences were found for number of fruits per plant and total production of the plant. The maximum productivity obtained was equal to $35,300 \mathrm{~kg} \mathrm{ha}^{-1}$ for a water depth of $443.9 \mathrm{~mm}$ and the optimum economic irrigation water depth was $443.5 \mathrm{~mm}$; higher economic returns are obtained by keeping the crop with a water content near field capacity, restoring the full amount of water consumed. The highest water use efficiency was $74.76 \mathrm{~kg} \mathrm{ha}^{1} \mathrm{~mm}^{-1}$ for a water depth of $334.1 \mathrm{~mm}$.
\end{abstract}

Key words: Capsicum annuum L., production function, economic great irrigation depth

Trabalho financiado pelo $\mathrm{CNPq}$

2 DEG/UFLA, CP 3037, CEP 37200-000, Lavras, MG. Fone: (35) 3829-1489. E-mail: jacintoc@deg.ufla.br; frezende@deg.ufla.br; reifaquino@ig.com.br; freitao@hotmail.com; eduardoco@oi.com.br 


\section{INTRODUÇÃO}

O pimentão (Capsicum annuum L.) é uma planta arbustiva, originária do continente americano, com sistema radicular pivotante e profundo, atingindo até $120 \mathrm{~cm}$ de profundidade. Seus frutos possuem alto teor de vitamina $\mathrm{C}$ e são utilizados na fabricação de condimentos, conservas, molhos, etc. É uma cultura que exige suprimento regular de água durante todo o ciclo; entretanto, o acúmulo de água no solo deve ser evitado para não favorecer o surgimento de doenças que podem causar apodrecimento do colo e raízes, assim como o abortamento e queda de flores. A deficiência de água é um dos fatores mais limitantes para a obtenção de elevadas produtividades, principalmente no cultivo de hortaliças em ambiente protegido ou em campo (Anthony \& Shingandhupe, 2004; Kirda et al., 2004; Guang-Cheng et al., 2008; Patanè \& Cosentino, 2010).

O cultivo em ambiente protegido tem sido utilizado, uma vez que permite obter produto de melhor qualidade, aumentar a produtividade e colocar no mercado um produto que, em condições de cultivo em campo, não seria possível. Entretanto, nesses ambientes a irrigação é imprescindível e o manejo inadequado do sistema de irrigação e da cultura pode inviabilizar o processo produtivo. Diversos autores têm comprovado que a irrigação promove aumento na produtividade de diversas hortaliças (Carvalho et. al., 2004; Vilas-Boas et al., 2008; Dermitas \& Ayas, 2009; Zeng et al., 2009; Bilibio et al., 2010), porém o manejo do sistema de irrigação deve propiciar condições adequadas para potencializar o desenvolvimento e a produtividade das culturas, além do que o manejo racional de um projeto de irrigação deve possibilitar maximização na eficiência do uso da água e minimizar os custos de investimento e operacionais, de forma que a atividade se torne economicamente viável e sustentável.

Frizzone et al. (2001) trabalharam com pimentão cultivado em casa de vegetação com o objetivo de estabelecer o nível de potencial mátrico da água no solo para determinar o momento de irrigação. Os autores verificaram que o potencial mátrico influenciou significativamente a produtividade, que foi maior quando a irrigação foi realizada quando o potencial mátrico da água no solo atingiu valor de $-15 \mathrm{kPa}$ controlado até $0,15 \mathrm{~m}$ de profundidade, até 56 dias após o transplantio e $0,40 \mathrm{~m}$ após os 56 dias.

Dermitas \& Ayas (2009), trabalhando com pimentão cultivado em casa de vegetação e irrigado por gotejamento, verificaram que a maior produtividade $\left(24 \mathrm{t} \mathrm{ha}^{-1}\right)$ foi obtida no tratamento que recebeu a maior lâmina $(724 \mathrm{~mm})$. Em contrapartida, Karan et al. (2009) observaram maior produtividade ( 31,9 t ha $^{-1}$ ) com lâmina de $427 \mathrm{~mm}$ para a mesma cultura. A diferença na produtividade verificada pelos autores pode ser devida à cultivar utilizada ou mesmo à época e local em que os experimentos foram conduzidos.

O efeito de três lâminas de irrigação (50, 75 e 100\% da ETc) e dois métodos de plantio na cultura do pimentão foi avaliado por Gadissa \& Chemeda (2009) que verificaram que a produtividade, o número de frutos por planta e a altura das plantas, foram maiores nos tratamentos irrigados com lâmina equivalente a $100 \%$ de ETc.
O declínio da disponibilidade de água para irrigação e os resultados positivos obtidos em algumas culturas, aumentaram o interesse no desenvolvimento de informações sobre irrigação deficitária (Dorji et al., 2005; Wakrim et al., 2005; Fereres \& Soriano, 2007). Nesta conformidade, o déficit hídrico pode trazer vantagens com a diminuição dos custos da irrigação, economia de água e, consequentemente, no que se refere ao meio ambiente.

Segundo Bernardo (2009), para quantificar os benefícios econômicos da irrigação é necessário saber quantificar o esperado aumento na produtividade, em função do aumento de água aplicada. A representação gráfica ou matemática desta relação é denominada função de produção "água-cultura". Segundo Reis et al. (2005), a função de produção representa uma relação técnica entre um conjunto específico de fatores envolvidos no processo produtivo e a produtividade física possível de se obter com a tecnologia aplicada.

Assim disposto, este trabalho foi realizado com o objetivo de avaliar, técnica e economicamente, o efeito de diferentes lâminas de irrigação aplicadas por gotejamento na produtividade do pimentão-vermelho cultivado em ambiente protegido.

\section{Material e MÉTOdos}

O experimento com a cultura do pimentão (Capsicum annuиm L.) cv. Konan R foi conduzido em casa de vegetação na área experimental do Departamento de Engenharia da Universidade Federal de Lavras, em Lavras, MG, localizada a $21^{\circ} 14^{\prime} 00^{\prime \prime}$ de latitude sul e $45^{\circ} 00^{\prime} 00^{\prime \prime}$ de longitude oeste a uma altitude média de $918 \mathrm{~m}$. O clima, de acordo com a classificação de Köppen, é caracterizado como Cwa, temperado úmido. A temperatura média do mês mais quente é de $22,8^{\circ} \mathrm{C}$, a do mês mais frio de $17,1^{\circ} \mathrm{C}$ e a média anual de $20,4^{\circ} \mathrm{C}$ (Dantas et al., 2007).

O solo da área experimental foi classificado como Latossolo Vermelho Distroférrico. A curva característica de água do solo foi determinada no Laboratório de Relação Água-Solo-Planta do Departamento de Engenharia da UFLA, cujas amostras foram coletadas nas camadas de 0,0 a $0,15 \mathrm{~m}$ de profundidade. Com os dados de umidade do solo associados às suas respectivas tensões, obteve-se o ajuste da curva de retenção de água no solo com o auxílio do software Soil Water Retention Curves (SWRC, versão 3.0), desenvolvido por Dourado Neto et al. (2000), que descrevem o comportamento da umidade do solo em função da tensão (Eq. 1).

$$
\theta=0,2350+\frac{(0,239)}{\left[1+(0,2749 \cdot|\psi|)^{2,0272}\right]^{0,5067}}
$$

em que:

$$
\begin{aligned}
& \theta \text { - umidade do solo }\left(\mathrm{cm}^{3} \mathrm{~cm}^{-3}\right) \\
& \Psi \text { - potencial mátrico }(\mathrm{kPa})
\end{aligned}
$$

No interior da casa de vegetação foi instalado um termohigrômetro para monitoramento de temperaturas e 
umidades relativas do ar, realizando-se as leituras pela manhã, diariamente, às $9 \mathrm{~h}$.

Utilizou-se delineamento experimental inteiramente casualizado (DIC), com 5 níveis de reposição de água no solo $(50,75,100,125$ e $150 \%)$ e 4 repetições, totalizando 20 parcelas experimentais, cada uma constituída de um canteiro com dimensões de $2,2 \times 0,3 \mathrm{~m}$, com espaçamento de $0,4 \mathrm{~m}$ entre plantas e 1,0 $\mathrm{m}$ entre canteiros.

As mudas foram formadas em bandejas de isopor com substrato comercial, por um produtor da região e transplantadas para os canteiros em outubro de 2007. As plantas de pimentão foram conduzidas em sistema de tutoramento utilizando-se estacas de bambu e fitas tipo fitilho. O desenvolvimento da parte aérea foi controlado retirandose as brotações laterais abaixo da bifurcação e eliminação das hastes acima da bifurcação, definindo quatro hastes a serem conduzidas. As flores e frutos da primeira bifurcação foram retirados. As adubações de plantio e de cobertura foram realizadas com base na análise de fertilidade do solo e de acordo com a recomendação da CFSEMG (1999). Foram aplicados $150 \mathrm{~kg} \mathrm{ha}^{-1}$ de N, $240 \mathrm{~kg} \mathrm{ha}^{-1}$ de $\mathrm{K}_{2} \mathrm{O}$ e $300 \mathrm{~kg} \mathrm{ha}^{-1}$ de $\mathrm{P}_{2} \mathrm{O}_{5}$. A adubação de plantio foi feita 15 dias antes do transplante das mudas adicionando-se $20 \%$ das doses de $\mathrm{N} \mathrm{e}$ $\mathrm{K}$, e todo o conteúdo de $\mathrm{P}$. Foram feitas 8 adubações de cobertura, adicionando-se todo o restante do N e K. As fontes de nutriente utilizadas foram a uréia, o cloreto de potássio e o superfosfato simples.

A irrigação foi realizada por meio de um sistema de gotejamento composto de uma linha lateral em cada canteiro e o manejo da irrigação foi feito a partir da leitura da tensão observada em três baterias de tensiômetros instalados a 0,15 $m$ de profundidade nas unidades experimentais, com $100 \%$ de reposição de água no solo. Realizaram-se as leituras por meio de um tensímetro digital com sensibilidade de $0,1 \mathrm{kPa}$ e o momento de irrigar foi definido quando a tensão média obtida nos tensiômetros atingia $15 \mathrm{kPa}$.

Obteve-se a tensão de água no solo equivalente à umidade na capacidade de campo através de teste in loco, obtendo-se o valor de $10 \mathrm{kPa}$. A lâmina aplicada foi calculada considerando-se a tensão média obtida, a curva de retenção de água no solo e a umidade relativa à capacidade de campo; as lâminas aplicadas em cada unidade experimental foram definidas de acordo com os percentuais relativos a cada tratamento e até 15 dias após o transplante das mudas todos os tratamentos foram irrigados com a mesma lâmina, de forma a garantir o pegamento e estabelecimento das mudas; após este período iniciou-se a aplicação dos diferentes níveis de reposição de água no solo.

A colheita dos frutos foi realizada em todas as plantas de cada parcela experimental, com início no dia 31/01/2008 (100 dias após o transplantio), quando apresentavam pelo menos $80 \%$ de sua superfície com a coloração vermelha e se estendeu até o dia 29/02/2008. Avaliaram-se o número de frutos por planta, o peso médio e a produtividade comercial da cultura. Os dados foram submetidos à análise de variância e a comparação de médias, quando significativas, foram estudadas por análise de regressão, utilizando-se o software SISVAR 5.0 (Ferreira, 2003).
Para obtenção da função de produção utilizou-se a análise de regressão entre a produção comercial e as lâminas de água, ajustada por um modelo polinomial de segunda ordem (Eq. 2).

$$
Y=f(W)=a+b W+c W^{2}
$$

em que:
Y - produtividade $\left(\mathrm{kg} \mathrm{ha}^{-1}\right)$
W - lâmina total de água aplicada (mm)
a, b e c - parâmetros da equação

Com a função ajustada determinou-se a lâmina de água $\left(\mathrm{W}_{\text {máx }}\right)$ que maximizou a produção (Eq. 3).

$$
\mathrm{W}_{\text {máx }}=\frac{-\mathrm{b}}{2 \mathrm{c}}
$$

A receita líquida, ou lucro da produção, foi obtida com a diferença entre o valor monetário total da produção e dos custos da aplicação de água e do custo fixo do sistema produtivo, incluindo-se o sistema de irrigação (Eq. 4).

$$
\mathrm{L}(\mathrm{W})=\mathrm{P}_{\mathrm{y}} \cdot \mathrm{Y}-\mathrm{P}_{\mathrm{w}} \cdot \mathrm{W}-\mathrm{C}
$$

em que:
$\mathrm{L}(\mathrm{W})$ - lucro $\left(\mathrm{R} \$ \mathrm{ha}^{-1}\right)$
$\mathrm{P}_{\mathrm{y}}$ - preço do pimentão $\left(\mathrm{R} \$ \mathrm{~kg}^{-1}\right)$
$\mathrm{Y}$ - produtividade do pimentão $\left(\mathrm{kg} \mathrm{ha}^{-1}\right)$
$\mathrm{P}_{\mathrm{w}}$ - preço do fator água $\left(\mathrm{R} \$ \mathrm{~mm}^{-1}\right)$
W - lâmina total de água aplicada ( $\mathrm{mm})$
C - custo dos fatores mantidos constantes no experimento $(\mathrm{R} \$)$

Visando à obtenção da maximização do lucro, calculou-se a derivada de primeira ordem da Eq. 2 em relação a $W$ e se igualou a derivada obtida à relação de preços do fator água $\left(\mathrm{P}_{\mathrm{w}}\right)$ e do produto $\left(\mathrm{P}_{\mathrm{y}}\right)$, obtendo-se a equação da lâmina ótima $\left(\mathrm{W}_{\text {ótima }}\right)$ que maximizou a receita (Eq. 5).

$$
\mathrm{W}_{\text {ótima }}=\frac{\mathrm{P}_{\mathrm{w}}-\mathrm{P}_{\mathrm{y}} \mathrm{b}}{2 \mathrm{P}_{\mathrm{y}} \mathrm{c}}
$$

Obteve-se o preço do pimentão $\left(\mathrm{P}_{\mathrm{y}}\right)$, referente ao período da colheita, junto às Centrais de Abastecimento de Minas Gerais, CEASA-MG (2008) que apresentaram o valor médio de $\mathrm{R} \$ 3,36 \mathrm{~kg}^{-1}$ durante este período. Para o custo da lâmina de água $\left(\mathrm{P}_{\mathrm{w}}\right)$, em $\mathrm{R} \$ \mathrm{~mm}^{-1}$, foram considerados dados médios do experimento utilizando-se a metodologia do cálculo do custo da energia para irrigação, conforme Carvalho et al. (1996); obteve-se, então, o custo da aplicação da lâmina unitária de $\mathrm{R} \$ 1,10$ dividindo-se o custo variável, para um hectare, pela lâmina total aplicada ao tratamento, considerando-se $100 \%$ de reposição da água, o que serviu como referencial para o reinício das irrigações. 


\section{RESULTADOS E DISCUSSÃO}

Os valores médios de temperatura máxima e mínima foram 37,2 e $17,3^{\circ} \mathrm{C}$, respectivamente, e a média durante o período foi de $28,4^{\circ} \mathrm{C}$. De acordo com Pinto et al. (2007), referidos valores estão próximos daqueles considerados ideais para o desenvolvimento e produção da cultura, uma vez que o crescimento vegetativo e a formação de frutos são favorecidos por temperaturas diurnas entre $25 \mathrm{e} 27^{\circ} \mathrm{C}$ e noturnas entre $7 \mathrm{e}$ $9{ }^{\circ} \mathrm{C}$ abaixo da temperatura média diurna. A média da umidade relativa do ar mínima durante o período foi de $33,0 \%$, e a umidade máxima e média foram de 90,1 e 61,6\%, respectivamente.

Na Tabela 1 são apresentados os valores das lâminas de irrigação aplicadas durante a experimentação, correspondentes aos níveis de reposição de água em cada tratamento.

Tabela 1. Percentuais de reposição de água e as correspondentes lâminas de irrigação aplicadas durante a condução do experimento

\begin{tabular}{cc}
\hline Níveis de reposição de água (\%) & Lâmina de irrigação (mm) \\
50 & 214 \\
75 & 321 \\
100 & 428 \\
125 & 535 \\
150 & 642 \\
\hline
\end{tabular}

Pela análise de variância (Tabela 2), pode-se observar que o número de frutos por planta, o peso médio dos frutos e a produtividade comercial, foram significativamente influenciados pelas lâminas de água repostas ao solo.

Tabela 2. Análise de variância para o número de frutos por planta (NFP), peso médio dos frutos (PMF) e produtividade comercial (PC) do pimentão cv. Konan R., em função das lâminas de irrigação

\begin{tabular}{lrccc}
\hline \multirow{2}{*}{ Fontes de variação } & \multirow{2}{*}{ GL } & \multicolumn{3}{c}{ Quadrado médio } \\
\cline { 3 - 5 } & & NFP & PMF (g) & PC (t ha ${ }^{-1}$ ) \\
Tratamento & 4 & $62,06^{* *}$ & $653,33^{* *}$ & $324,64^{* *}$ \\
Resíduo & 15 & 17,18 & 55,99 & 27,83 \\
C.V. (\%) & 17,18 & 9,23 & 36,32 \\
Média & & 16,49 & 146,03 & 26,17 \\
\hline ** significativo a 1\% de probabilidade, pelo teste F & &
\end{tabular}

** significativo a $1 \%$ de probabilidade, pelo teste $\mathrm{F}$

Através da Figura 1A verifica-se que o peso médio de frutos produzidos por planta apresentou variação parabólica com a lâmina de irrigação, atingindo um máximo correspondente a 164,4 g para uma lâmina de $428 \mathrm{~mm}$, decrescendo a partir deste ponto. A análise de regressão aplicada aos dados de peso médio indica que o modelo descreveu bem o fenômeno para o intervalo considerado, com um coeficiente de determinação $\left(\mathrm{R}^{2}\right)$ de $91,36 \%$. Sezen et al. (2006) verificaram que o peso médio dos frutos de pimentão foi significativamente influenciado pela lâmina e frequência de irrigação e que o peso do fruto aumentou com o aumento da frequência de irrigação.

O número de frutos por planta (NFP), resultado de cinco colheitas, foi significativamente influenciado pelos tratamentos a $1 \%$ de probabilidade. O número médio de frutos por planta, considerando-se todos os tratamentos de irrigação, obteve

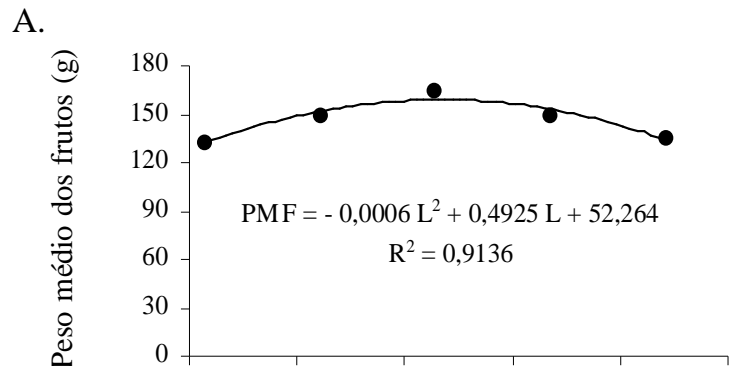

B.

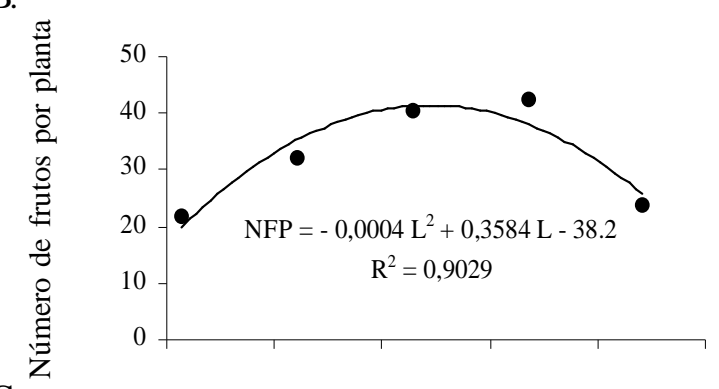

C.

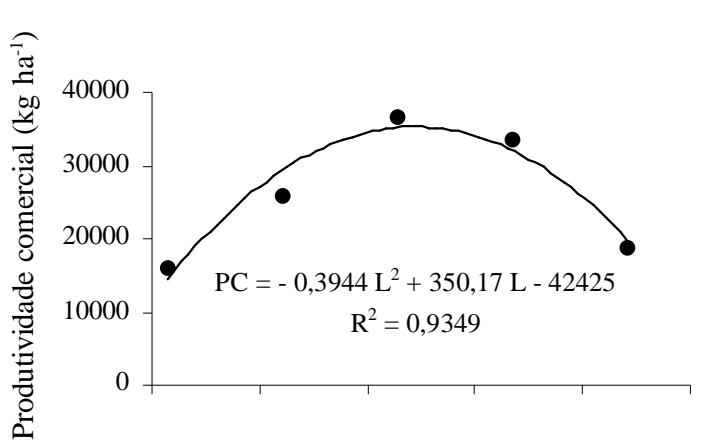

D.

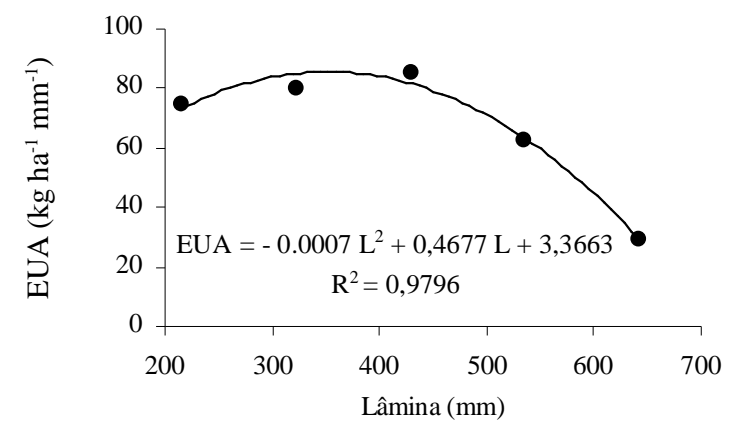

Figura 1. Peso médio dos frutos $(A)$, número de frutos por planta (B), produtividade comercial (C) e eficiência do uso da água - EU A (D) de pimentão Cv. Konan R., em função de diferentes lâminas de irrigação

valor de 16,49. O maior número de frutos por planta foi obtido no tratamento de $125 \%$ de reposição da lâmina (Tabela 1). Trabalhando com pimentão irrigado, e adotando três níveis de lâmina (50, 75 e 100\% da ETc) e dois métodos de plantio, Gadissa $\&$ Chemeda (2009) verificaram que o número de frutos foi maior nos tratamentos irrigados com 100\% de ETc, com valor médio, para os dois sistemas de plantio, de 55 frutos por planta. Resultados obtidos por Frizzone et al. (2001) com o pimentão amarelo indicam que o maior número de frutos maduros foi obtido no tratamento que recebeu a maior lâmina de água.

A equação da Figura 1B sinaliza o coeficiente de determinação $\left(R^{2}\right)$ de $90,29 \%$, demonstrando que o modelo quadrático adotado 
representa adequadamente o comportamento do número de frutos por planta em função das lâminas de irrigação utilizadas na cultura do pimentão cv. Konan R.

Considerando a produção média por planta e uma população de 12.000 plantas ha $^{-1}$, obteve-se a produtividade do pimentão em função das lâminas de água (Figura 1C). O modelo quadrático ajustado aos dados da produtividade média, indicou ajuste adequado, explicando 93,49\% das ocorrências. Anthony \& Shingandhupe (2004), trabalhando com pimentão irrigado por gotejamento e aplicando lâminas equivalentes a 100, 80, 60 e 40\% da evaporação do tanque Classe $\mathrm{A}$, verificaram que a maior produtividade por planta foi obtida no tratamento que recebeu $100 \%$ da evaporação do tanque Classe A e que a taxa de acréscimo na produtividade entre os tratamentos de 80 e $100 \%$ da evaporação do tanque, foi de $39,84 \%$. Os autores ainda observaram relação quadrática entre a produtividade e a lâmina aplicada.

Para os valores médios da eficiência do uso da água (EUA) constatou-se diferença estatística significativa entre os tratamentos aplicados a $1 \%$ de probabilidade. A eficiência na utilização da água (EUA) foi ajustada a uma equação polinomial de segundo grau, apresentando comportamento quadrático, com 97,96\% de representatividade (Figura 1D). Deste modo, o maior valor de eficiência (EUA) foi estimado em 74,76 kg ha-1 $\mathrm{mm}^{-1}$ para uma lâmina de $334,1 \mathrm{~mm}$

Pode-se observar que o conceito de eficiência do uso da água é relativo, ou seja, maior eficiência não significa maior produtividade. Para a maior eficiência encontrada, a produtividade estimada foi de $30.542 \mathrm{~kg} \mathrm{ha}^{-1}$. A eficiência do uso da água traduz a taxa de conversão do fruto, isto é, a quantidade de matéria fresca que está sendo produzida para cada unidade de água aplicada.

A partir da função de produção estimada para a produção comercial do pimentão-vermelho, obteve-se a máxima produtividade física do fator água, calculados pela Eq. 6, também chamada produto físico marginal (PFMa), para cada lâmina de água aplicada (Tabela 3).

$$
\frac{\partial \mathrm{Y}}{\partial \mathrm{W}}=-0,7888 \cdot \mathrm{W}+350,17=\frac{\mathrm{P}_{\mathrm{w}}}{\mathrm{P}_{\mathrm{y}}}
$$

Observa-se que o PFMa é, inicialmente, positivo, e decresce sempre que se aumenta a lâmina de irrigação aplicada ao solo (Tabela 3). A partir do ponto em que o PFMa apresentou valor nulo, a aplicação da maior lâmina de irrigação conduziu ao valor de produto físico marginal negativo, indicando não ser econômico recomendar o uso dessa quantidade de água (utilização excessiva de água).

Nota-se, ainda, que após o ponto de máxima produção, quando o PFMa é nulo, a aplicação de maiores lâminas de água proporciona

Tabela 3. Produto físico marginal (PFMa) para as diferentes lâminas de água aplicadas na cultura do pimentão CV. Konan R.

\begin{tabular}{cr}
\hline Lâminas de irrigação $(\mathbf{m m})$ & (PFMa) \\
214 & 181,37 \\
321 & 96,97 \\
428 & 12,56 \\
535 & $-71,84$ \\
642 & $-156,24$ \\
\hline
\end{tabular}

valores negativos de PFMa (Tabela 3). Este comportamento apresenta ou caracteriza o estágio de produção antieconômico, pois o acréscimo das lâminas aplicadas acarreta diminuição da produção.

Considerando fixo o preço do pimentão $\left(\mathrm{P}_{\mathrm{y}}\right)$, verifica-se que, incrementando-se o preço da água $\left(\mathrm{P}_{\mathrm{w}}\right)$, a lâmina total de irrigação a se aplicar, deve ser menor para que o produtor obtenha o lucro máximo na atividade. Para atender às diferentes relações entre o preço da água e o preço do pimentão vermelho, construiu-se um gráfico relacionando-se a lâmina de irrigação economicamente ótima ( $\left.\mathrm{W}_{\text {ótima }}\right)$, em função da relação de preços entre fator água e produto $\left(\mathrm{P}_{\mathrm{w}} / \mathrm{P}_{\mathrm{y}}\right)$, demonstrado na Figura 2.

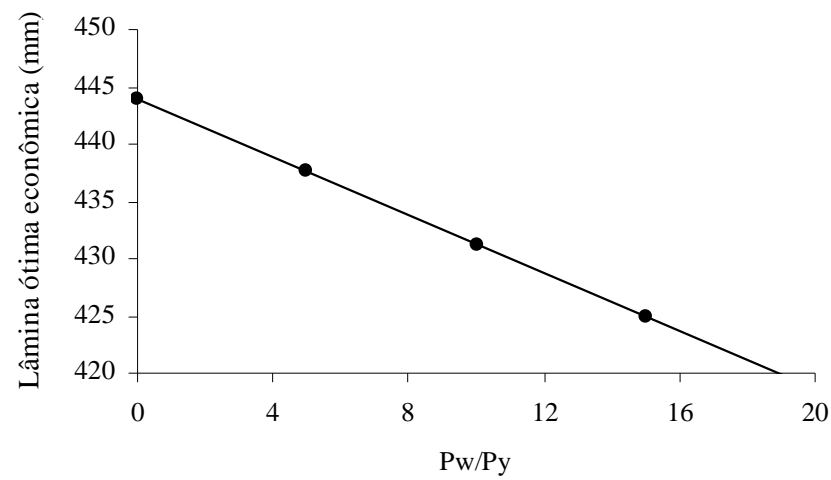

Figura 2. Lâmina total de água ótima econômica, em função da relação entre o preço da água $\left(P_{w}\right)$ e o preço do produto $\left(P_{y}\right)$, em função das diferentes lâminas de reposição de água no solo, para a cultura do pimentão cv. Konan R

Observa-se que a lâmina total de irrigação economicamente ótima decresce à medida que se aumenta a relação entre preços $\left(\mathrm{P}_{\mathrm{w}} / \mathrm{P}_{\mathrm{y}}\right)$. Assim, considerando-se fixo o preço médio da comercialização do pimentão-vermelho, verifica-se que, incrementando-se o custo da água como, por exemplo, devido ao aumento da tarifa de energia para pressurização do sistema de irrigação, ou pela cobrança do uso da água, a lâmina total de irrigação a se aplicar deve ser menor para que o produtor obtenha o lucro máximo na atividade.

A máxima produtividade estimada é de $35.300 \mathrm{~kg} \mathrm{ha}^{-1}$ para uma lâmina de $443,9 \mathrm{~mm}$ e a maior rentabilidade foi obtida com a aplicação da lâmina de 443,5 mm para a mesma produtividade. Fazendo-se uma análise comparativa entre a lâmina ótima econômica e a lâmina que gera a máxima produtividade física, observam-se semelhantes valores de produtividade. Logo, ao se aplicar a lâmina de água que proporcione a máxima produtividade física, ela poderá ser suficiente para alcançar uma produtividade economicamente viável, indicando que a irrigação deve ser feita de forma a manter as condições ótimas de umidade no solo e garantir o desenvolvimento vegetativo da cultura do pimentão-vermelho. Valores muito próximos entre a lâmina ótima econômica e a lâmina que gerou a maior produtividade, foram observados por Lima Júnior et al. (2010) para a cultura da alface americana irrigada.

Apesar da importância da irrigação no processo produtivo de hortaliças em ambiente protegido, a baixa eficiência na condução de água, na distribuição pelos sistemas e na aplicação aos cultivos, motiva a otimização do uso da água, enfocando prioritariamente a eficiência produtiva da cultura (Oliveira, 2009). Nesta conformação, as relações entre as lâminas de água aplicada e as eficiências de uso de água obtidas, permitem determinar a máxima eficiência técnica da cultura do pimentão 
vermelho na utilização da água no processo de transformação em produto comercializável.

\section{ConclusõEs}

1. O excesso e/ou déficit de água foi, de maneira geral, prejudicial à cultura do pimentão.

2. A máxima produtividade estimada foi de $35.300 \mathrm{~kg} \mathrm{ha}^{-1}$ para uma lâmina de $443,9 \mathrm{~mm}$ de água.

3. A lâmina ótima econômica foi estimada em 443,5 mm indicando que maiores retornos econômicos foram obtidos repondo integralmente a quantidade de água consumida.

4. A maior eficiência no uso da água foi estimada em 74,76 $\mathrm{kg} \mathrm{ha}^{-1} \mathrm{~mm}^{-1}$ com a aplicação de $334,1 \mathrm{~mm}$.

\section{Agradecimentos}

Ao Conselho Nacional de Desenvolvimento Científico e Tecnológico (CNPq), pelo financiamento do projeto.

\section{LITERATURA CITADA}

Anthony, E.; Shingandhupe, R. B. Impact of drip and surface irrigation on growth, yield and WUE of capsicum (Capsicum annuum L.). Agricultural Water Management, v.65, p.121132, 2004.

Bernardo, S. Manejo da Irrigação na cana-de-açúcar. <http:// www.agencia.cnptia.embrapa.br/Repositorio/Cana_irrigada_ producao_000fizvd3t102wyiv802hvm3jlwle6b8.pdf >.01 Mar. 2009.

Bilibio, C.; Carvalho, J. de A.; Martins, M. A.; Rezende, F. C.; Freitas, E. A.; Gomes, L. A. A. Desenvolvimento vegetativo e produtivo da berinjela submetida a diferentes tensões de água no solo. Revista Brasileira de Engenharia Agrícola e Ambiental, v.14, p.730-735, 2010.

Carvalho, J. de A.; Bernardo, S.; Sousa, E. F. Cálculo do custo de energia para irrigação. Campos dos Goytacazes: UENF, 1996. 13p. Boletim Técnico 1,

Carvalho, J. de A.; Santana, M. J. de; Pereira, G. M.; Pereira, J. R. D.; Queiroz, T. M. de. Níveis de déficit hídrico em diferentes estádios fenológicos da cultura de berinjela (Solanum melongena L.). Engenharia Agrícola, v.24, p.320-327, 2004.

CEASAMG - Centrais de Abastecimento do Estado de Minas Gerais. Boletim diário de preços. <http://minas.ceasa.mg.gov.br /detec/boletim/boletimproduto/boletim_produto.php >. 20 Fev. 2008.

CFSEMG - Comissão de Fertilidade do Solo do Estado de Minas Gerais. Recomendações para o uso de corretivos e fertilizantes em Minas Gerais: $5^{a}$ aproximação. Viçosa: UFV, 1999. 359p.

Dantas, A. A. A.; Carvalho, L. G. de; Ferreira, E. Classificação e tendências climáticas em Lavras, MG. Ciência e Agrotecnologia, v.31, p.1862-1866, 2007.

Dermitas, C.; Ayas, S. Deficit irrigation effects on pepper (Capsicum annuum L. Demre) yield in unheated greenhouse condition. Journal of Food, Agricultural and Environment, v.7, p.989-1003, 2009.

Dorji, K., Behboudian, M. H., Zegbe-Dominguez, J. A. Water relations, growth, yield and fruit quality of hot pepper under deficit irrigation and partial rootzone drying. Scientiae Horticulturae, v.105, p.138-149, 2005.
Dourado Neto, D.; Nielsen, D. R.; Hopmans, J. W.; Reichardt, K.; Bacchi, O. O. S. Software to model soil water retention curves (SWRC, version 3.00). Scientia Agricola, v.57, p.191-192, 2000.

Fereres, E.; Soriano, A. Deficit irrigation for reducing agricultural water use. Journal of Experimental Botany, v.58, p.147-159, 2007.

Ferreira, D. F. Programa de análises estatísticas (statistical analysis sotware) e planejamento de experimentos -SISVAR 5.0 (Build 67). Lavras: DEX/UFLA, 2003.

Frizzone, J. A.; Gonçalves, A. C. A.; Rezende, R. Produtividade do pimentãoamarelo, Capsicum annuum L., cultivado em ambiente protegido, em função do potencial mátrico de água no solo. Acta Scientiarum, v.23, p.1111-1116, 2001.

Gadissa, T.; Chemeda, D. Effects of drip irrigation levels and planting methods on yield and yield components of green pepper (Capsicum annuum, L.) in Bako, Ethiopia. Agricultural Water Management, v.96, p.1673-1678, 2009.

Guang-Cheng, S.; Yu, Z.Z.; NA, L.; Shuang-En. Y.; Xeng-Gang, X. Comparative effects of deficit irrigation (DI) and partial rootzone drying (PRD) on soil water distribution, water use, growth and yield in greenhouse grown hot pepper. Scientiae Horticulturae, v.119, p.11-16, 2008.

Karan, F.; Masaad, R.; Bachour, R.; Rhayem, C.; Rouphael, Y. Water and radiation use efficiencies in drip-irrigated pepper (Capsicum annuит L.): Response to full and deficit irrigation regimes. European Journal of Horticultural Science, v.74, p.79-85, 2009.

Kirda, C.; Cetin, M.; Dasgan, Y.; Topcu, S.; Kaman, H.; Ekici, B.; Derici, M. R.; Ozguven, A. I. Yield response of greenhouse grown tomato to partial root drying and conventional deficit irrigation. Agricultural Water Management, v.69, p.191-201, 2004.

Lima Júnior, J.A. de; Pereira, G M.; Geisenhoff, L. O.; Costa, G. G; Vilas Boas, R.C.; Yuri, J.E. Efeitodairrigaçãosobreorendimentoprodutivo da alface americana, em cultivo protegido. Revista Brasileira de EngenhariaAgrícola eAmbiental, v.14, p.797-803, 2010.

Oliveira, E. C. Manejo de irrigação da cultura do pepino japonês (Cucumis sativus L.) em ambiente protegido. Lavras: UFLA, 2009. 108p. Dissertação Mestrado

Patanè, C.; Cosentino, S. L. Effects of soil water deficit on yield and quality of processing tomato under a mediterranean climate. Agricultural Water Management, v.97, p.131-138, 2010.

Pinto, C. M. F.; Moreira, G R.; Caliman, F. R. B.; Venzon, M.; Picanço, M. C.; Paula Júnior, T. J. Pimentão. In: Paula Júnior, T. J.; Venzon, M. 101 culturas: Manual de tecnologia agrícola. Belo Horizonte: EPAMIG 2007. p.641-650

Reis, R. P.; Takaki, H. R. C.; Reis, A. J. dos. Como calcular o custo de produção. Lavras: UFLA, 2005. 15p.

Sezen, S. M.; Yazar, A.; Eker, S. Effect of drip irrigation regimes on yield and quality of field grown bell pepper. Agricultural Water Management, v.81, p.115-131, 2006.

Vilas-Boas, R. C.; Carvalho, J. de A.; Gomes, L. A. A.; Sousa, A. M. G. de; Rodrigues, R. C.; Souza, K. D. de. Avaliação técnica e econômica da produção de duas cultivares de alface tipo crespa em função de lâminas de irrigação. Ciência e Agrotecnologia, v.32.p.525-531, 2008.

Wakrim, R.;Wahbi, S.; Tahi, H.; Aganchich, B.; Serraj, R. Comparative effect of partial root drying (PRD) and regulated deficit irrigation (RDI) on water relation sand water use efficiency in common bean (Phaseolous vulgaris L.). Agriculture, Ecosystems \& Environment, v.106, p.275-287, 2005.

Zeng, C.; Bie, Z.; Yuan, B. Determination of optimum irrigation water amount for drip-irrigated muskmelon (Cucumis melo L.) in plastic greenhouse. Agricultural Water Management, v.96, p.595-602, 2009. 